\title{
A mechanical method for monitoring and data visualisation of small deformations in underground structures
}

\author{
H Zhang Kobe University, Japan \\ S Akutagawa Kobe University, Japan
}

\begin{abstract}
In recent years, an onsite visualisation method was proposed to measure the deformation of structure and to visualise the measured results by different colours of light in real time for personnel conducting field measurement. Based on this concept, a mechanical method is introduced in this paper to monitor the small deformations in underground structures such as cracks in the concrete lining of a tunnel. It consists of a rotational structure which is used to transform the linear relative displacement into the movement of rotation. The other component is a small mirror which is mobilised to rotate by the rotational structure. An observer can see the reflected image of the coloured mark in the mirror from a certain distance. If the mirror rotates when displacement happens, the reflected image of the mark would move at the same time and eventually disappear from the mirror. As a result, the displacement can be identified visually by the changing reflected image of the coloured mark and its value can be read directly from the width of the shifted mark. The mirror size and the distance between the observer and the mirror determine the precision of the method for measurement. In this paper, the fundamental experiments were carried out to verify the feasibility and effectiveness of the method. The authors believe that this mechanical method could improve the safety management of tunnelling, mining and rock slope engineering.
\end{abstract}

\section{Introduction}

Deformation monitoring can provide an intuitive insight into the stability of underground structures during the construction and in-service stage because of the uncertainty of the loading condition in underground engineering. In conventional measurement, the data of measured deformations are usually processed by data loggers or computers and the results are analysed by professionals. The workers are not the first to be aware of the state of structures during construction. When an unexpected deformation occurs, an in-time alarm shall be helpful in avoiding loss of life and allow countermeasures to be taken to prevent the accident from taking place. In addition, the number of measuring points of the structure is often reduced to the minimum due to cost consideration which diminishes the ability to effectively evaluate the safety of structure.

Therefore, a new monitoring scheme called onsite visualisation (Akutagawa 2010; Akutagawa et al. 2011; 2013) is proposed to measure the deformation and visualise the results using different colours of light in real-time. It aims to help improve safety management of the structures during their lifecycle. A series of light-emitting sensors based on this concept have been employed to monitor the deformations of structures in various construction projects (Izumi et al. 2014). At the same time, simple but effective sensors are in demand at construction sites because the cost of measurement needs to be controlled at a low level. For example, an optical method was tested to monitor the inclination of the slope using a mirror (Akutagawa et al. 2014a). The mirror is set up at the measuring point so that the ground and the mirror can move together. The observer can identify the inclination of the ground by the movement of image of the light-emitting diode (LED) light reflected from the mirror. This method is called the single observation point (SOP) because multiple points can be monitored at the same time while only one light source is needed. 
In this paper, we make improvements to the SOP method in order to visualise a relative displacement of structure. As shown in Figure 1, firstly, the linear relative displacement is converted into the rotation by a rotational structure. Secondly, the rotation angle can be monitored visually with a small mirror. Finally, the relative displacement can be obtained by judging the width of the shift of the mirrored colour stripes. The fundamental idea of this method and the laboratory test is introduced here to verify the feasibility of this method. Some applications of this method are discussed briefly to draw out the future work of this research.

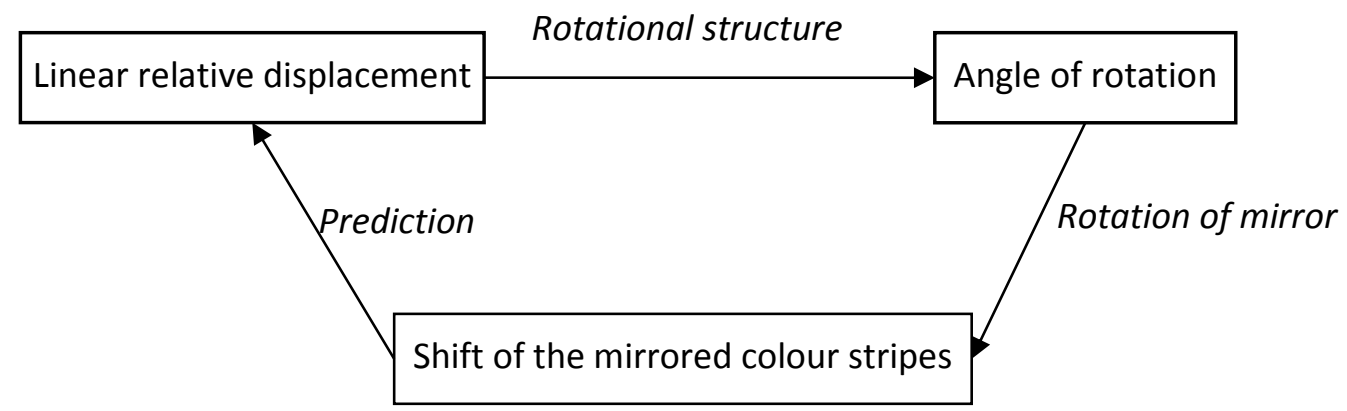

\section{Figure 1 Procedure of visualisation of a displacement}

\section{Visualisation of rotation angle}

\subsection{Mechanism of the optical method}

The relative displacement monitoring is premised on the basis of a precise angle measurement. The mirror refection is made use of discretely in the research. A rectangular plane mirror is chosen (Figure 2). In Figure 3, the plane mirror is set up at a distance $I(\mathrm{OP})$ from the observer. The width of the mirror is $d$ $\left(M_{1} M_{2}\right)$. At the same place of the observer, the width of visible zone reflected by the mirror shall be $2 d(A B)$. Assuming that the mirror rotates around its central axis by the angle $\theta$ while the observer keeps stable, the mirrored zone shifts to $A^{\prime} B^{\prime}$ accordingly, whose width remains $2 d\left(A^{\prime} B^{\prime}\right)$. In other words, Line $A B$ can be seen at Point $P$ at the initial phase. As the mirror rotates gradually to an angle of $\theta$, the range of the initial visible zone $(A B)$ narrows simultaneously and, finally, Line $A B$ disappears from the view. Therefore, the rotation could be identified by checking the shift of the mirrored zone. It is noted that the reference in the mirrored zone and the observation Point $\mathrm{P}$ should be stable during the monitoring.

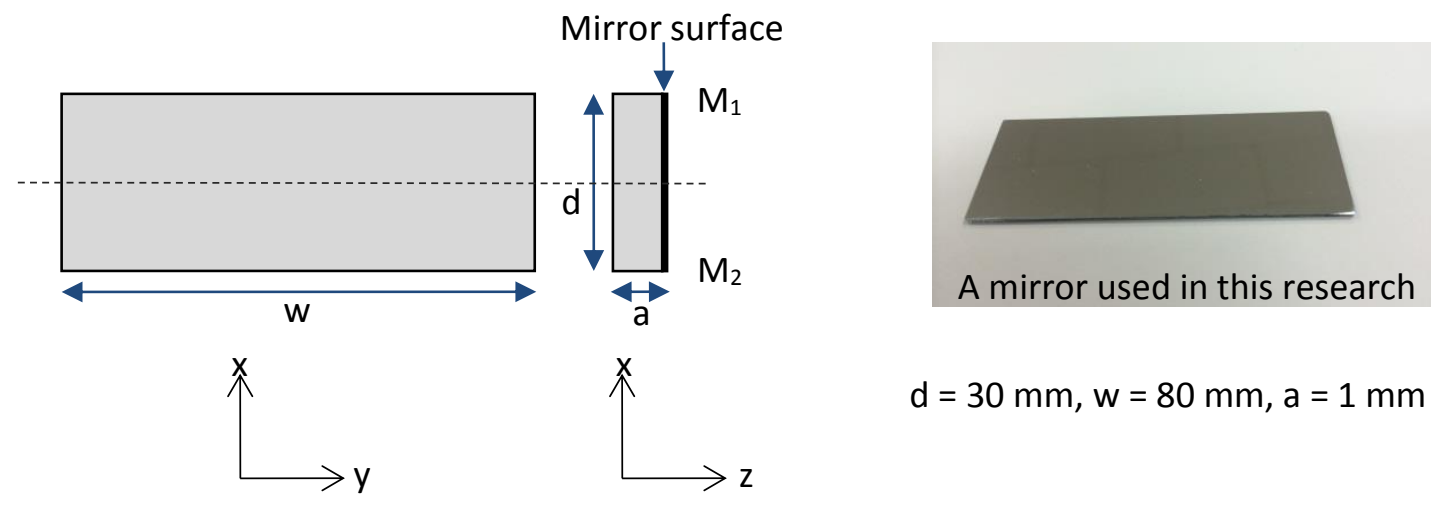

Figure 2 A rectangular plane mirror 


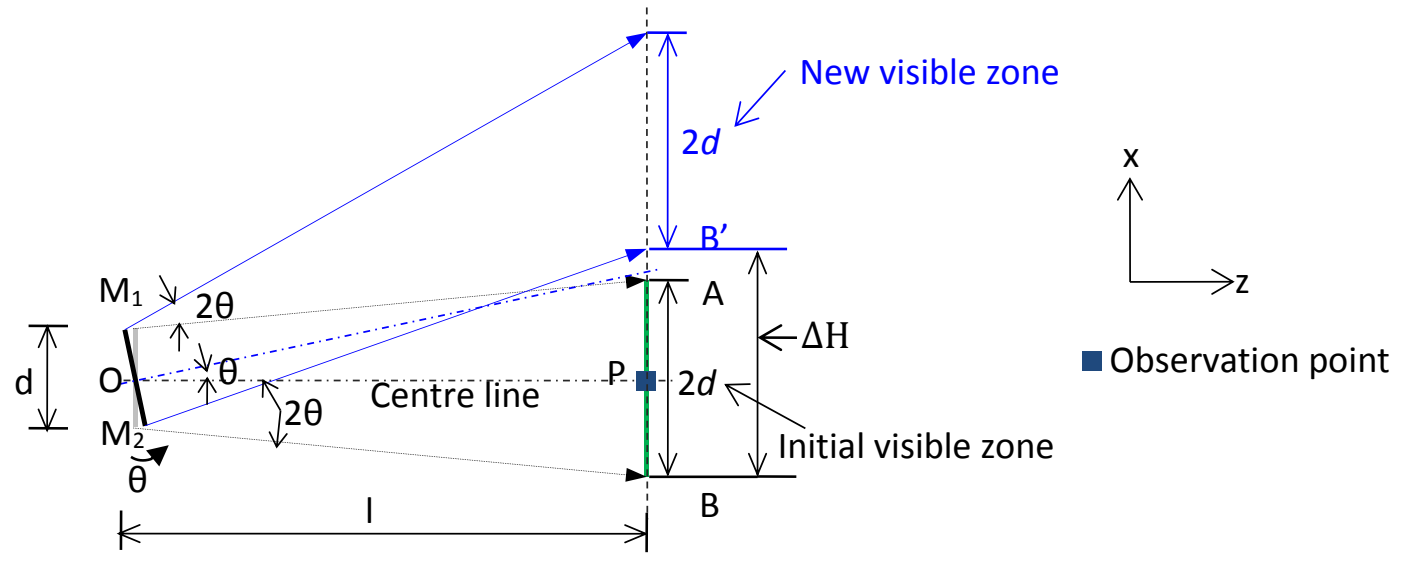

\section{Figure 3 Light reflection from a plane mirror (xz-plane)}

A colour panel with blue, red, yellow and green stripes is designed as the reference in the mirrored zone (Figure 4). Each of the colour stripes has a width of $2 d$, equal to the width of the visible zone from the mirror. At first, the green stripe is adjusted to fill the range of the visible zone completely. If the mirror begins to rotate to an angle of $\theta$ in the xz-plane, the reflected image of the panel will shift from green stripe to yellow stripe, to red stripe, and to blue stripe (Figure 5). The relationship of a complete shift of one stripe $(\Delta \mathrm{H}=2 d$ (Figure 3$))$, the rotation angle, the distance between the mirror and the observation point are expressed as follows:

$$
\begin{gathered}
2 \theta \times I=2 d \\
\theta=d / I
\end{gathered}
$$

where:

$$
\begin{aligned}
& d \quad=\text { the width of mirror. } \\
& \theta \quad=\text { the rotation angle. } \\
& I \quad=\text { the distance between the mirror and the observation point. }
\end{aligned}
$$

It is found that a larger ' $"$ ' and a smaller ' $d$ ' could result in a more precise measurement of the rotation angle. However, the visibility of the reflected image of the panel would be poor if a very high precision is pursued. A proper sized mirror and appropriate observation distance should be determined for better visibility in monitoring.
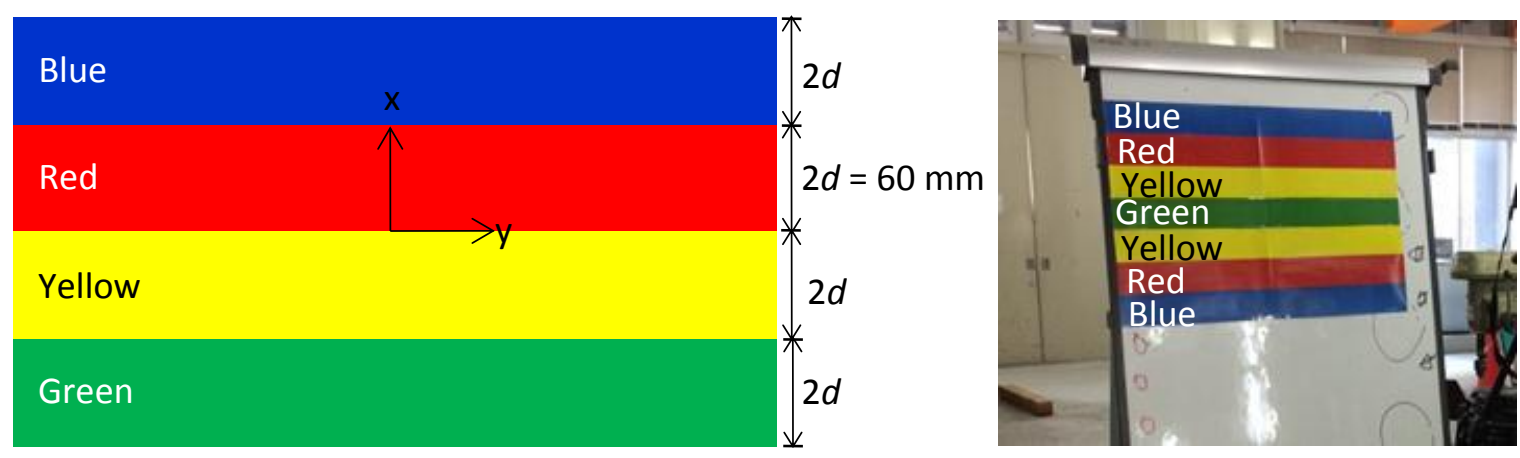

Figure 4 Colour panel as a reference 


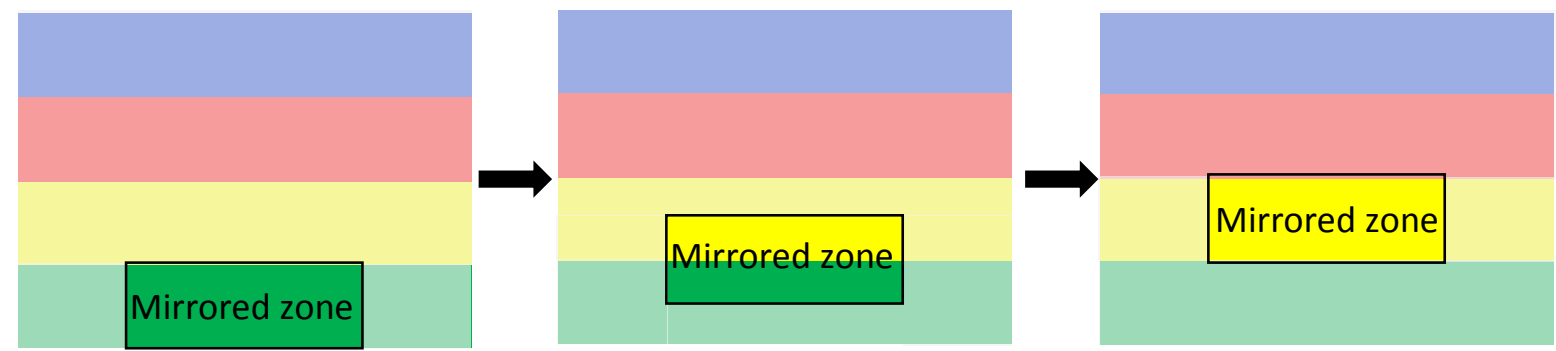

Figure 5 Shift of the colour stripe reflected from the mirror

\section{$2.2 \quad$ Laboratory experiment}

\subsubsection{Experiment description}

An experiment of a simply supported beam was carried out under different centre loads, employing the optical method to monitor the rotation angle of the beam. The visibility and sensitivity of the method for rotation measurement could be checked. As shown in Figure 6 , the aluminium beam is supported by the rollers at its ends $A$ and $E$. The colour panel is set up along the extension Line AF of the beam, $11.21 \mathrm{~m}$ away from Point A. The observation point is close to the colour panel which is perpendicular to Line AF. As shown in Figure 7, a digital camera at the observation point is used to record the reflected image of the colour panel. The material parameters of the aluminium beam are shown in Table 1. Three mirrors are set up at Points A, B and C in the beam's neutral plane. The rotation angles of each mirror corresponding to the shift of colour stripes are summarised in Table 2. The shift of the same colour stripe in the three mirrors suggests a slightly different rotation angle because the distance between the mirror and each observation point is different. The defections of the beam at Points B, C and D are measured by the linear variable differential transformers (LVDT).

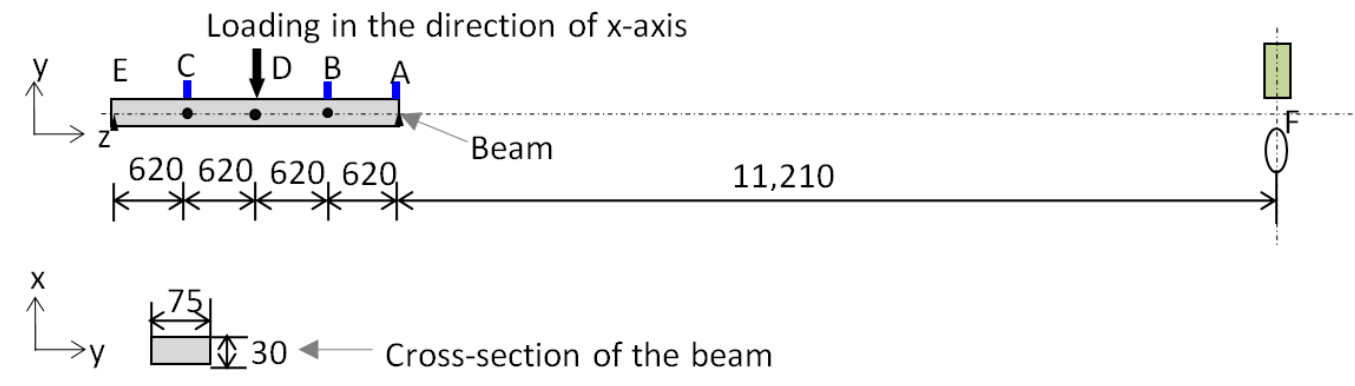
I Mirror
Colour panel
Observation point $\quad$ - LVDT
Unit: $\mathrm{mm}$

\section{Figure 6 Experimental set-up and instrumentation (side view)}
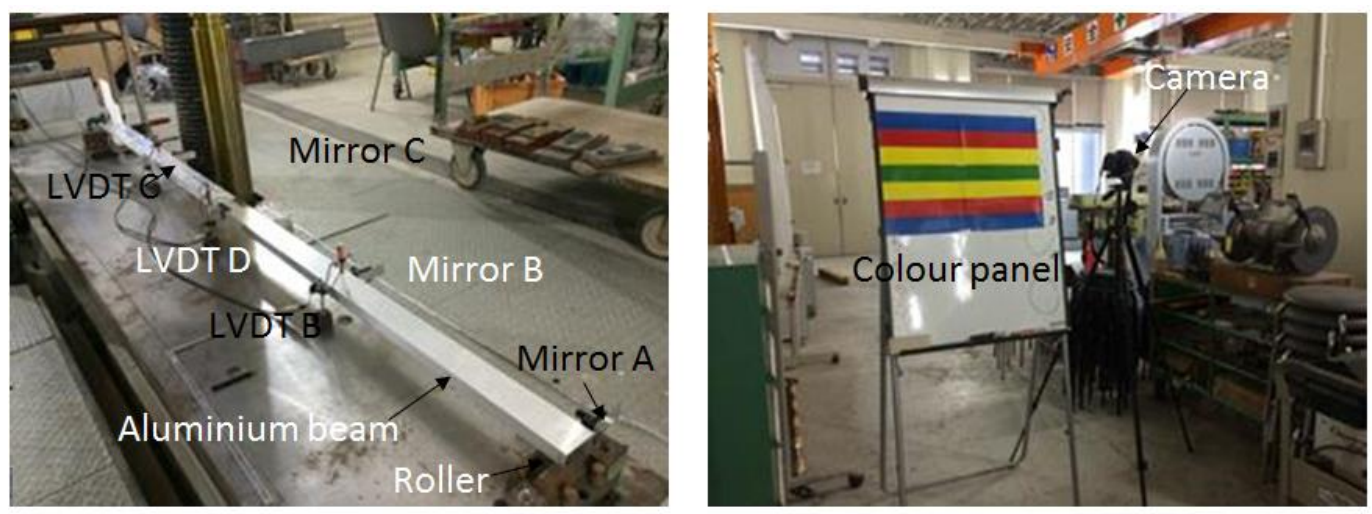

Figure $7 \mathrm{~A}$ view of the experiment 
Table 1 Parameters of aluminium beam

\begin{tabular}{|c|c|c|c|c|}
\hline \multicolumn{3}{|c|}{ Beam size } & \multirow{2}{*}{$\begin{array}{c}\text { Young's Modulus, } E \\
\left(\mathrm{~N} / \mathrm{m}^{2}\right)\end{array}$} & \multirow{2}{*}{$\begin{array}{l}\text { Moment of Inertia, I } \\
\qquad\left(\mathrm{m}^{4}\right)\end{array}$} \\
\hline Span (m) & Width (m) & Height(m) & & \\
\hline 2.480 & 0.075 & 0.030 & $7.0 \times 10^{10}$ & $1.686 \times 10^{-7}$ \\
\hline
\end{tabular}

Table 2 Rotation angles measured by different mirror

\begin{tabular}{cccccc}
\hline Mirror & $\begin{array}{c}\text { Distance between mirror and } \\
\text { observation point }(\mathrm{m})\end{array}$ & $\begin{array}{c}\text { Green } \\
\text { (degree) }\end{array}$ & $\begin{array}{c}\text { Yellow } \\
\text { (degree) }\end{array}$ & $\begin{array}{c}\text { Red } \\
\text { (degree) }\end{array}$ & $\begin{array}{c}\text { Blue } \\
\text { (degree) }\end{array}$ \\
\hline A & 11.210 & 0 & 0.1534 & 0.3068 & 0.4602 \\
B & 11.830 & 0 & 0.1454 & 0.2907 & 0.4361 \\
C & 13.070 & 0 & 0.1316 & 0.2632 & 0.3947 \\
\hline
\end{tabular}

\subsubsection{Result analysis}

A load of $9.8 \mathrm{~N}, 98 \mathrm{~N}, 196 \mathrm{~N}$ and $294 \mathrm{~N}$ in series is applied to the aluminium beam at its midpoint D. Table 3 shows the comparison of the deflections between experimental results and those obtained from theory, which confirms that the aluminium beam remains elastic under the centrally applied load.

Table 3 Deflection of the beam

\begin{tabular}{|c|c|c|c|c|c|c|c|c|c|}
\hline \multirow{3}{*}{$\begin{array}{c}\text { Applied } \\
\text { load } \\
\text { (N) }\end{array}$} & \multicolumn{9}{|c|}{ Deflection in the direction of $x$-axis ( $\mathrm{mm}$ ) } \\
\hline & \multicolumn{3}{|c|}{ B } & \multicolumn{3}{|c|}{ C } & \multicolumn{3}{|c|}{ D } \\
\hline & $\begin{array}{l}\text { Theo. } \\
\text { value }\end{array}$ & $\begin{array}{l}\text { Measured } \\
\text { value }\end{array}$ & $\begin{array}{l}\text { Relative } \\
\text { error } \\
\text { (\%) }\end{array}$ & $\begin{array}{l}\text { Theo. } \\
\text { value }\end{array}$ & $\begin{array}{l}\text { Measured } \\
\text { value }\end{array}$ & $\begin{array}{l}\text { Relative } \\
\text { error } \\
\text { (\%) }\end{array}$ & $\begin{array}{l}\text { Theo. } \\
\text { value }\end{array}$ & $\begin{array}{l}\text { Measured } \\
\text { value }\end{array}$ & $\begin{array}{c}\text { Relative } \\
\text { error } \\
\text { (\%) }\end{array}$ \\
\hline 9.8 & 0.181 & 0.175 & 3.4 & 0.181 & 0.171 & 5.6 & 0.264 & 0.250 & 5.1 \\
\hline 98 & 1.812 & 1.822 & 0.5 & 1.812 & 1.830 & 1.0 & 2.636 & 2.597 & 1.5 \\
\hline 196 & 3.625 & 3.668 & 1.2 & 3.625 & 3.678 & 1.5 & 5.272 & 5.210 & 1.2 \\
\hline 294 & 5.437 & 5.516 & 1.4 & 5.437 & 5.520 & 1.5 & 7.908 & 7.822 & 1.1 \\
\hline
\end{tabular}

This allows for the comparison of the rotation angles between theoretical and experimental results. The reflected images of the colour panel are recorded by the camera (Figure 8 ). It can be found that the reflected colour stripes shift accordingly as the load increases.

The results of measured angles are shown in Table 4 along with the theoretical values. At the supports, Points $A$ and $E$, there are only rotations while the deflections are zero. Note that the deflections at the measuring points $B$ and $C$ will influence the final results of rotation angle. For example, the deflection at Point $B$ is $5.5 \mathrm{~mm}$ under the load of $294 \mathrm{~N}$. The proportion of effect $(\gamma)$ due to the deflection is given by:

$$
\gamma=\frac{2 u}{v} \times \%=\frac{2 u}{w+2 u} \times \%
$$

where:

\footnotetext{
$u=$ the offset of the mirror in the direction of $x$-axis, equal to the deflection at the measuring point of the beam.

$v=$ the true total amount of the shift of reflected image from the mirror.

$w=$ the measured total amount of the shift of reflected image from the mirror.
} 
Thus, at the measuring point $B, \gamma=\frac{2 \times 5.5}{153+2 \times 5.5} \times \%=6.7 \%$.

When its deflection is $0.17 \mathrm{~mm}$ at the loading of $9.8 \mathrm{~N}$, the proportion of effect is about $0.17 \times 2 / 6=5.7 \%$. Therefore, the effect could be ignored when the displacement of the mirror is very small. In this case, a small angle of rotation could be measured and visualised appropriately by the mirror.

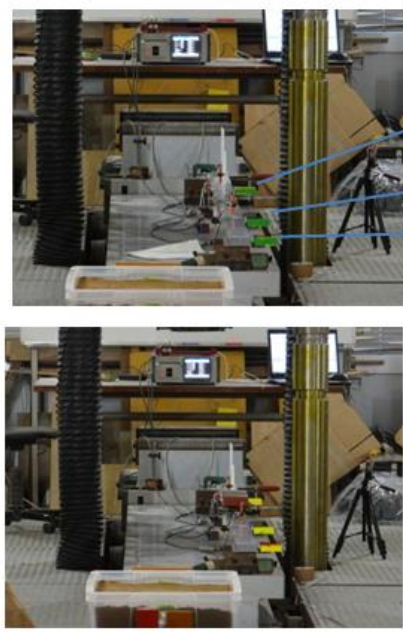

(d)
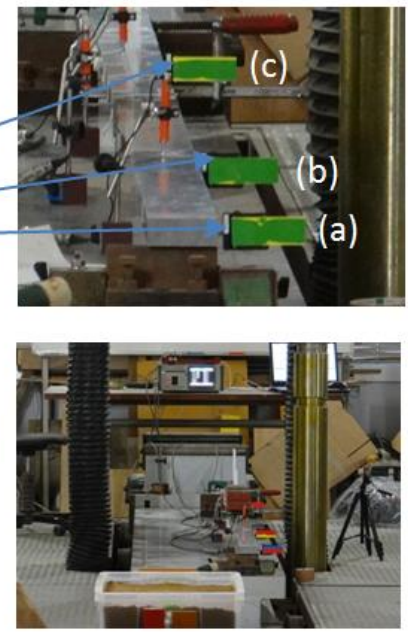

(e)
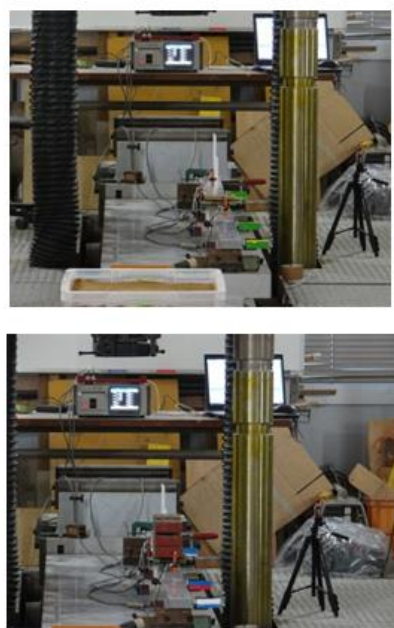

(f)

Figure 8 Reflected colour stripe from the mirror under different loads; (a) origin; (b) partial enlargement of the mirrored green stripe; (c) $9.8 \mathrm{~N}$; (d) $98 \mathrm{~N}$; (e) $196 \mathrm{~N}$; (f) $294 \mathrm{~N}$

Table 4 Rotation angles measured by the mirror and the corresponding theoretical value

\begin{tabular}{|c|c|c|c|c|c|c|c|c|c|}
\hline \multirow{3}{*}{$\begin{array}{l}\text { Applied } \\
\text { load } \\
\text { (N) }\end{array}$} & \multicolumn{9}{|c|}{ Rotation angle (degree) } \\
\hline & \multicolumn{3}{|c|}{ A } & \multicolumn{3}{|c|}{ B } & \multicolumn{3}{|c|}{ C } \\
\hline & $\begin{array}{l}\text { Theo. } \\
\text { value }\end{array}$ & $\begin{array}{l}\text { Measured } \\
\text { value }\end{array}$ & $\begin{array}{c}\text { Relative } \\
\text { error } \\
(\%)\end{array}$ & $\begin{array}{l}\text { Theo. } \\
\text { value }\end{array}$ & $\begin{array}{c}\text { Measured } \\
\text { value }\end{array}$ & $\begin{array}{l}\text { Relative } \\
\text { error } \\
\text { (\%) }\end{array}$ & $\begin{array}{l}\text { Theo. } \\
\text { value }\end{array}$ & $\begin{array}{l}\text { Measured } \\
\text { value }\end{array}$ & $\begin{array}{c}\text { Relative } \\
\text { error } \\
\text { (\%) }\end{array}$ \\
\hline 9.8 & 0.0183 & 0.0199 & 8.97 & 0.0137 & 0.0145 & 6.13 & 0.0137 & 0.0145 & 5.66 \\
\hline 98 & 0.1828 & 0.1918 & 4.90 & 0.1371 & 0.1439 & 4.99 & 0.1371 & 0.1448 & 5.58 \\
\hline 196 & 0.3656 & 0.3758 & 2.80 & 0.2742 & 0.2545 & -7.20 & 0.2742 & 0.2645 & -3.53 \\
\hline 294 & 0.5484 & 0.5676 & 3.50 & 0.4113 & 0.3707 & -9.88 & 0.4113 & 0.4210 & 2.36 \\
\hline
\end{tabular}

\section{Visualisation of a small displacement}

\subsection{Mechanism of the small displacement sensor}

As shown in Figure 9, a linear displacement can be transformed into the arc curve by the rotational structure, such as the pulley. The rotation angle is able to be attained by the optical method which is tested in Section 2. Combining these two functions, a mechanical sensor is proposed to monitor a relative displacement. A relative displacement between two points can be detected and transformed into rotation in some ways, including the wire-pulley type and the rigid rack-pinion type (Figure 10). For wire-pulley type, the relative displacement is measured in the direction of line of Points 1 and 2. For rack and pinion type, 
the relative displacement is measured along the axis of the rack. The mirror is fixed on the rotational structure so that both could have an identical angle of rotation.

The relationship between relative displacement and rotation angle is given by:

$$
\begin{aligned}
& \because S=R \times \theta^{\prime} \\
& \therefore \theta^{\prime}=S / R
\end{aligned}
$$

where:

$S \quad=$ a relative displacement between two points.

$\theta^{\prime} \quad=$ the rotation angle of rotational structure.

$R=$ radius of rotational structure.

Since the mirror has the same rotation angle as the rotational structure, we can have:

$$
\theta=\theta^{\prime}
$$

In case of a full shift of one colour stripe reflected from the mirror, from Equations 2 and 5 , we can derive that:

$$
\begin{aligned}
& \theta=\mathrm{d} / \mathrm{I}=\mathrm{S} / \mathrm{R} \\
& \therefore S=R \cdot d / I
\end{aligned}
$$

where:

$$
\begin{aligned}
& d \quad=\text { the width of mirror. } \\
& l \quad=\text { the distance between the mirror and the observation point. }
\end{aligned}
$$

It is therefore found that the precision of this mechanical displacement sensor is determined by the width of mirror $(d)$, the radius of axis of rotational structure $(R)$ and the distance between mirror and observation point (I).

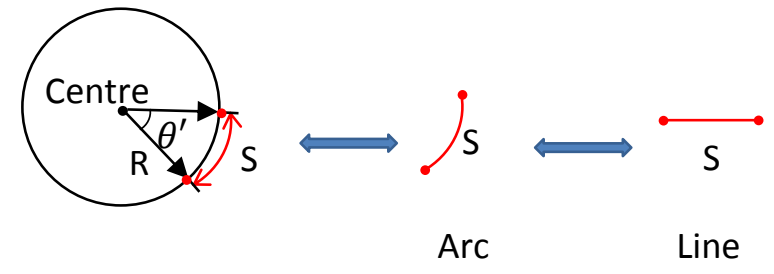

Figure 9 Displacement transformation between an arc and a line

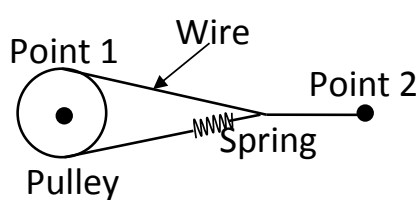

a) Wire-pulley type

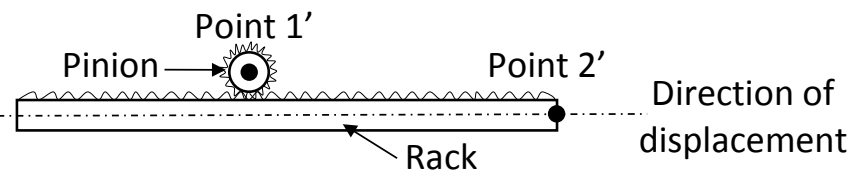

b) Rack-pinion type

Figure 10 Different rotational structures for displacement transformation

\subsection{Experimental design}

There are two structures for transforming the linear displacement into the rotation (Section 3.1). The idea of using the pulley and wire has been applied to visualise the relative displacement of mountain linings by the rotation of a plastic needle attached on the side of pulley in a tunnel construction (Akutagawa et al. 2014b). In this research, a structure of rack-pinion type is adopted because it seems to be a more reliable 
way to detect a small relative displacement between two points. A similar experiment of a simply supported beam under different loads was carried out to verify the feasibility of the displacement sensor (Figure 11). A load of $0.98 \mathrm{~N}, 1.96 \mathrm{~N}, 2.94 \mathrm{~N}, 3.92 \mathrm{~N}$ and $4.9 \mathrm{~N}$ in series is applied at the centre of the beam. The deflection at midpoint $\mathrm{D}$ is monitored by this mechanical displacement sensor (Figure 12). In this section, information about the mechanical displacement sensor using the mirror is discussed. The observation distance of Line DF is $10 \mathrm{~m}$. The radius of the pinion is $7.96 \mathrm{~mm}$. The displacements measured by mirror $\mathrm{D}$ corresponding to the full shift of different colour stripes are summarised in Table 5.

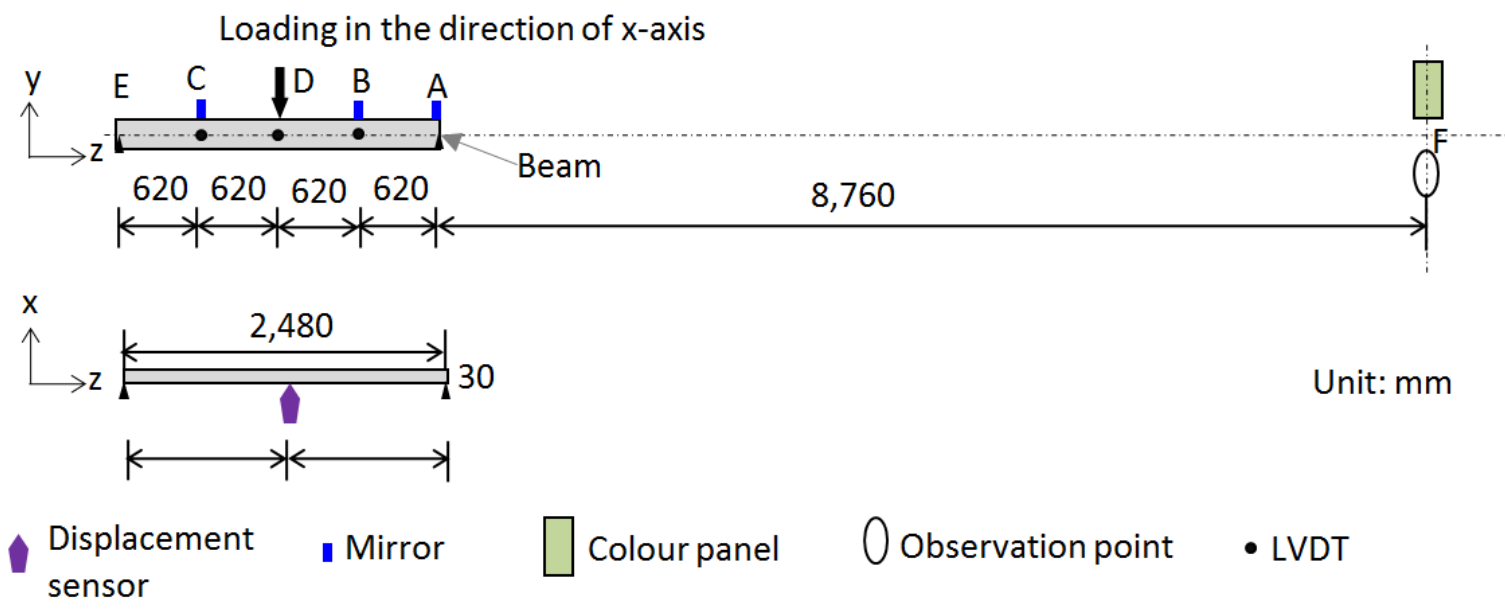

Figure 11 Experimental setup and instrumentation using the displacement sensor
Table 5 Displacements measured by mirror $D$ according to different reflected colour strips

\begin{tabular}{cccccc}
\hline Mirror & $\begin{array}{c}\text { Distance between mirror and } \\
\text { observation point }(\mathbf{m})\end{array}$ & $\begin{array}{c}\text { Green } \\
(\mathbf{m m})\end{array}$ & $\begin{array}{c}\text { Yellow } \\
(\mathbf{m m})\end{array}$ & $\begin{array}{c}\text { Red } \\
(\mathbf{m m})\end{array}$ & $\begin{array}{c}\text { Blue } \\
(\mathbf{m m})\end{array}$ \\
\hline $\mathrm{D}$ & 10.000 & 0 & 0.02 & 0.04 & 0.07 \\
\hline
\end{tabular}
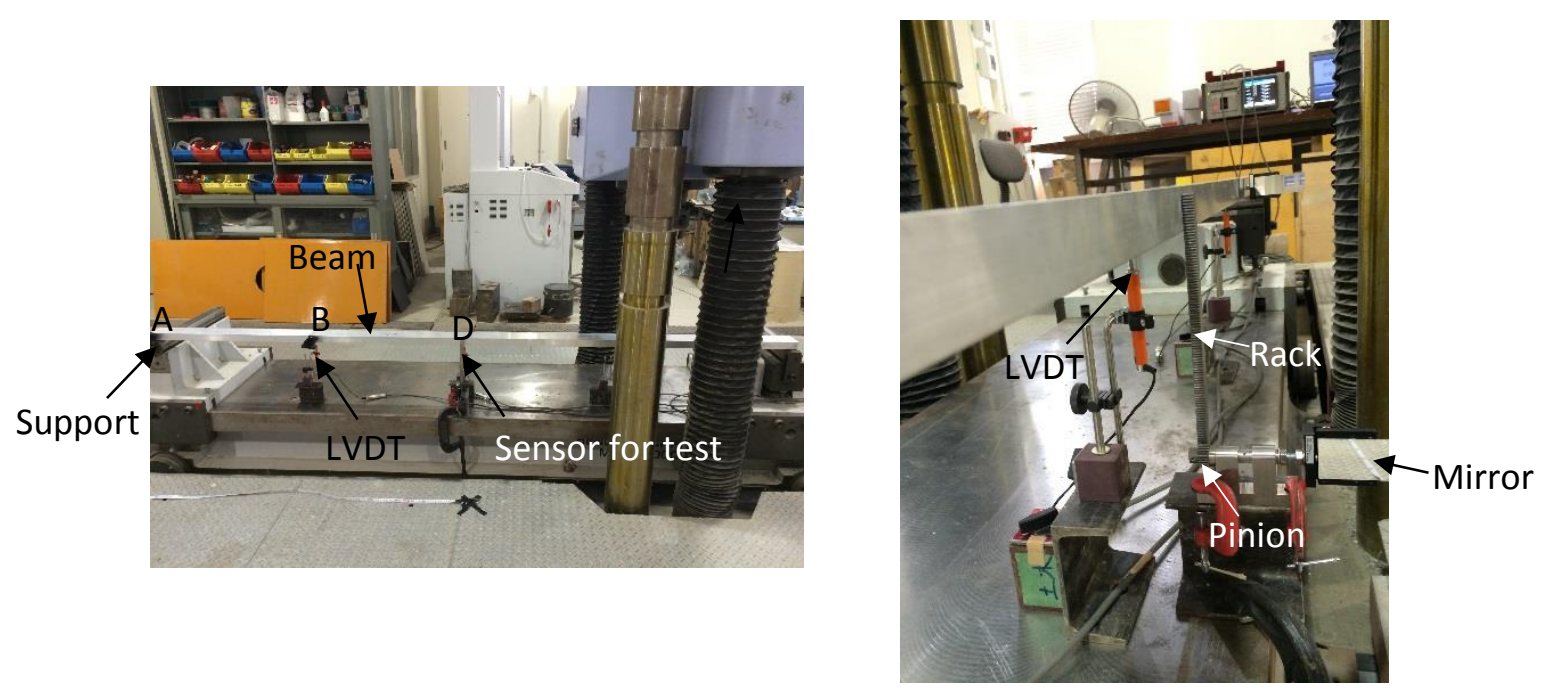

Figure 12 Simply supported beam monitored by the displacement sensor

\subsection{Result analysis}

The mirror is set up at the station which remains stable during monitoring. Therefore, the mirror is mobilised to rotate by the rack without any offset when the displacement occurs. The reflected images of 
the colour stripes are recorded by the camera (Figure 13). The reflected colour stripes from the mirror shift correspondingly to applied loads. As soon as the load of $4.9 \mathrm{~N}$ is applied, the deflection is too large to be measured by the sensor. The results of measured displacements by the sensor and LVDT are shown in Table 6. It was found that the values measured by LVDT are not in accordance with the theoretical values, suggesting that a simply supported beam experiment is not ideal for the testing of very small loads. The loading method, the weight of measuring devices and the supports etc. might have much influence on the final results. Therefore, the measured values by the displacement sensor are analysed in comparison with those measured by LVDT. The results in Table 6 show that a displacement as small as $0.1 \mathrm{~mm}$ can be measured roughly and visualised by this mechanical displacement sensor using the mirror.

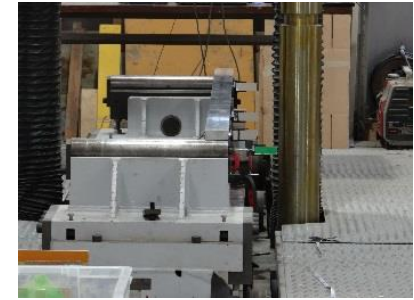

(a)

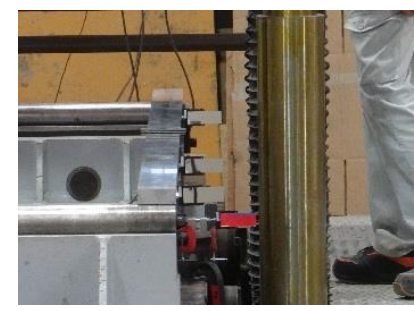

(d)

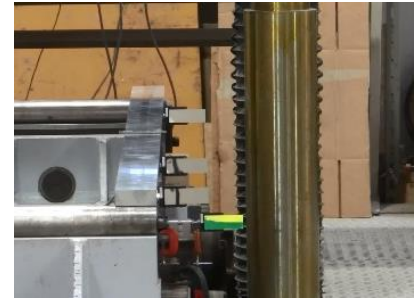

(b)

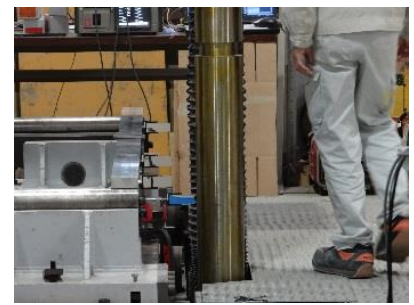

(e)

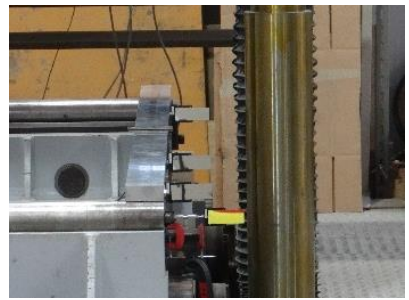

(c)

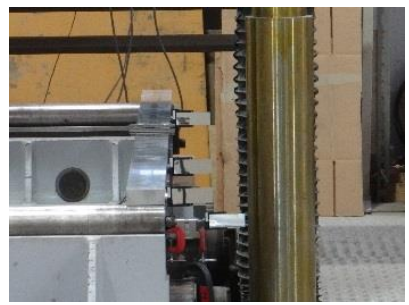

(f)

Figure 13 Reflected colour stripe from the mirror under different loads: (a) origin; (b) $0.98 \mathrm{~N}$; (c) $1.96 \mathrm{~N}$; (d) $2.94 \mathrm{~N}$; (e) $3.92 \mathrm{~N}$; (f) $4.9 \mathrm{~N}$

Table 6 Deflection of the beam at midpoint $D$

\begin{tabular}{cccccc}
\hline $\begin{array}{c}\text { Deflection at midpoint } \mathbf{D} \\
(\mathbf{m m})\end{array}$ & $\mathbf{0 . 9 8}$ & $\mathbf{1 . 9 6}$ & $\mathbf{2 . 9 4}$ & $\mathbf{3 . 9 2}$ & $\mathbf{4 . 9}$ \\
\cline { 2 - 6 } & 0.0095 & 0.0287 & 0.0502 & 0.0812 & - \\
\hline Measured value by sensor & 0.009 & 0.035 & 0.055 & 0.110 & 0.112 \\
Measured value by LVDT & 0.0264 & 0.0527 & 0.0791 & 0.1055 & 0.1318 \\
Theoretical value & 6.13 & -18.1 & -8.82 & -26.1 & - \\
Relative error (\%) & & & & & \\
\hline
\end{tabular}

\section{Discussion}

The mechanical method using a mirror is introduced to measure and visualise small relative displacements. There are two important factors to consider when doing the accuracy analysis. The first is the rotation angle visualised by the mirror. The use of a precision manufactured mirror is highly recommended in this method. Otherwise the edge of the mirrored colour stripe might not be straight, which makes it difficult to identify the rotation angle correctly. The temperature of the surroundings also has some effect on the mirror's properties. A stable room temperature is preferred during monitoring. The other fact is the detection of the linear displacement which is transformed into the rotational movement. Further research on a reliable and proper structure should be carried out. In addition, the observer is required to monitor the mirror at the same point every time. Since a small displacement like $1 / 50 \mathrm{~mm}$ can be identified in this 
mechanical method, any tiny influence during monitoring could lead to a large relative error of the measured result.

Small relative displacements are usually measured by precision electric instruments. The intention of this method is to visualise small displacements mechanically. The observer is able to find the small displacement by identifying the change of the reflected colour stripes from the mirror. The results in Tables 4 and 6 are estimated from the reflected image of colour stripes which shows an acceptable precision. Meanwhile, this method for displacement monitoring can be carried out without using electricity which makes it attractive in the long-term safety management of the structures. It is thought to be a promising method to be applied in monitoring cracks in underground structures, movement of rock in a slope, and the supporting structures in mining engineering where small relative displacements inevitably occur.

\section{Conclusion}

A mechanical method is introduced to monitor and visualise small linear displacements in structures based on the concept of onsite visualisation. Its mechanism lies in that linear displacement is transformed into the rotation angle which can be identified by making use of the mirror reflection law. Laboratory experiments confirm the feasibility of visualisation of the rotation angle and small displacement. The influence factors are discussed briefly and should be taken care of in practice.

\section{Acknowledgement}

The work was supported by the research project (2012-2014) 'Development of low-cost and low-power consuming monitoring system based on on-site visualisation' funded by the Ministry of Land, Infrastructure, Transport and Tourism, Government of Japan.

\section{References}

Akutagawa, S 2010, 'On site visualization as a new paradigm for field measurement in rock engineering', Proceedings of the 6th Asian Rock Mechanics Symposium, India, New Delhi, pp. 34-45.

Akutagawa, S, Minami, Y, Haba, T, Hiroshima, T\& Nozawa, T 2011, 'A new method for visualizing stresses in rock support measures by using a light emitting sensor', in Q Qian \& Y Zhou (eds), Proceedings of the 12th ISRM Congress, Harmonising Rock Engineering and the Environment, Taylor \& Francis Group, London, pp. 403-407.

Akutagawa, S, Nakata, K, Nishio, A \& Yamada, H 2014a, 'Single observation point method for measurement and real-time visualization of inclination using a mirror for rock engineering projects', Proceedings of the 8th Asian Rock Mechanics Symposium, pp. 2433-2441.

Akutagawa, S, Zhang, H, Terashima, M \& Tsujimura, K 2013, 'Measurement and real-time visual presentation of the ground deformation ahead of mountain tunnel face using optical fibers', in X-T Feng, JA Hudson \& F Tan (eds), Proceedings of the Sinorock Symposium for the 3rd International Society for Rock Mechanics, Rock Characterisation, Modelling and Engineering Design Methods, Taylor \& Francis Group, London, pp. 759-762.

Akutagawa, S, Zhang, H, Terashima, M \& Tsujimura, K 2014b, 'A mechanical method for monitoring and visualization of deformations of tunnel structures', Proceedings of the 8th Asian Rock Mechanics Symposium, pp. 2309-2316.

Izumi, C, Akutagawa, S, Ravi, C, Kataria, R, Abe, R \& Haga, H 2014, 'On-site visualization monitoring for long span bridge on Delhi Metro Project', Current Science, vol. 106, no. 9, pp. 1280-1290. 